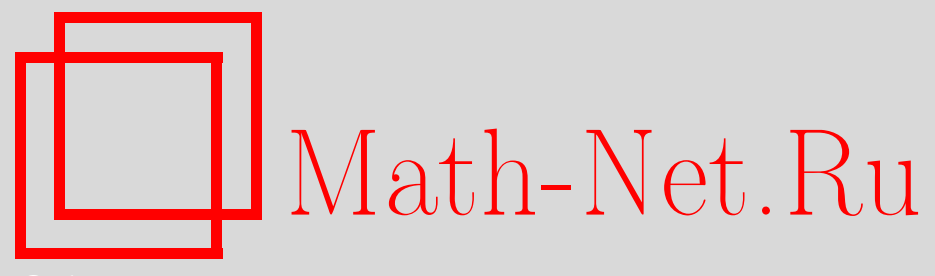

А. Минеев, «Вирус», «маска» - где гарантия?, Квант, 2020, номер 11, 2-7

DOI: https://doi.org/10.4213/kvant20201101

Использование Общероссийского математического портала Math-Net.Ru подразумевает, что вы прочитали и согласны с пользовательским соглашением http://www.mathnet.ru/rus/agreement

Параметры загрузки:

IP : 54.164 .48 .24

26 апреля 2023 г., $13: 39: 43$

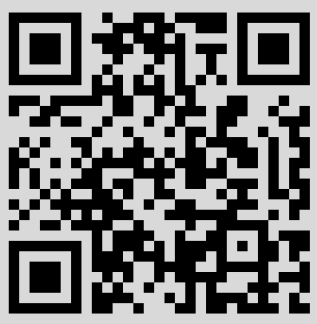




\section{«Вирус», «маска» где гарантия?}

A. МИНЕEB
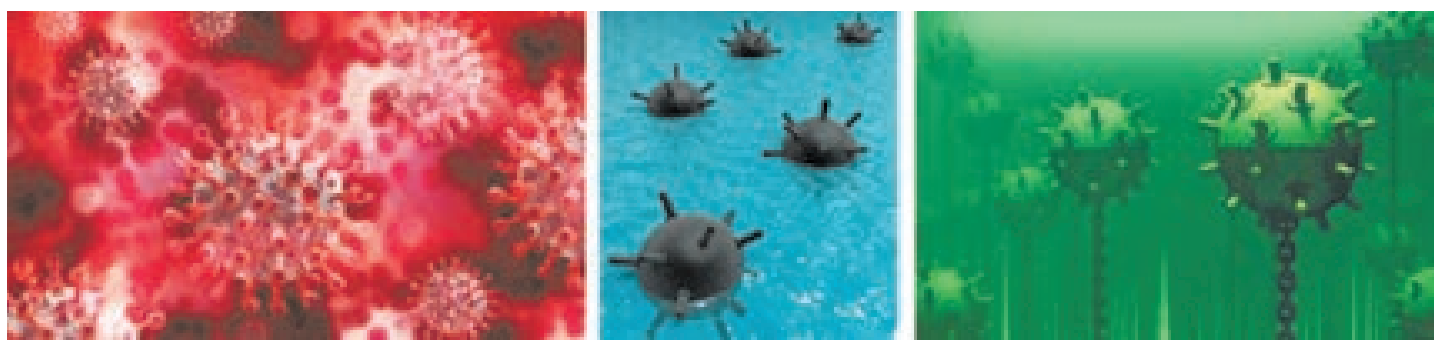

Рис. 1. Слева - коронавирусы, в центре и справа - «рогатые» морские мины

ТА СТАТЬЯ - ПРО НЫНЕШНЮЮ

эпидемию коронавируса, про то, нужно ли носить маски, дают ли они гарантию от заражения и так ли важна абсолютная защита от вируса. Но начнем с нескольких примеров из истории развития техники - с того, какие «маски» для защиты от каких «вирусов» там применяются.

\section{Защита кораблей от магнитных мин}

Посмотрите на рисунок 1. Не правда ли, сразу возникает странная зрительная аналогия между обликом коронавируса и «рогатой» морской миной. Проблема защиты кораблей от таких мин была очень острой в период до и во время второй мировой войны, хотя она сохраняет свою актуальность и сейчас. ${ }^{1}$ Но особую опасность представляют магнитные мины.

В конструкцию больших морских кораблей всегда входят магнитные материалы, в первую очередь - ферромагнитная сталь.

1 Подробнее об этом можно прочитать, например, в статье И.Кикоина «Физики - фронту» («Квант», 1985, №5) и в статье В.Регеля, Б.Ткаченко «Размагничивание кораблей в годы Великой Отечественной войны» («Квант», 1980, №5). (Прим. ред.)

DOI: https://doi.org/10.4213/kvant20201101
Намагничивание кораблей происходит как во время их стоянки (при постройке или в порту), так и в ходе движения, когда меняется положение корабля относительно магнитного поля Земли. Магнитные домены частично выстраиваются вдоль поля, и материал намагничивается. В этом случае опасность для надводных и подводных объектов представляют магнитные мины, реагирующие на возмущение магнитного поля при их движении. Это можно уподобить «вирусу» того времени.

Опасность сильно возросла из-за того, что после первой мировой войны Германия по Версальскому договору потеряла флот и целенаправленно развивала и совершенствовала программу создания и использования как контактных мин типа изображенных на рисунке 1, так и более опасных бесконтактных магнитных мин.

Магнитные мины, как показал опыт первых месяцев второй мировой войны, оказались весьма грозным оружием, сравнительно простым в установке (с самолетов, с кораблей и подводных лодок). Причем существенно более опасным, чем применение мин на суше против танков (сравните стоимость танка и военного корабля с экипажем).В поисках «масок» - средств защиты от этого «вируса» - в мире наметилось в то время несколько направлений: 
- полное размагничивание корабля;

- намагничивание корабля до максимальных значений, с тем чтобы мины взрывались на безопасном расстоянии;

- неполная компенсация магнитного поля корабля - до уровня, когда мина перестает замечать корабль на фоне магнитного поля Земли.

Первое направление активно поддерживали флотские минеры, но в ходе реализации оно оказалось технически слишком сложным. В переводе на язык современной эпидемии COVID-19 это соответствует идеальной маске или появлению вакцины, гарантирующей безопасность.

Противоположного первому второго направления сначала (середина 1930-х годов) придерживалась Великобритания, однако на практике сильное намагничивание корабля не помогло полностью уберечь от магнитных мин. Опять переводя на язык COVID-19 - пусть все переболеют, а кто выживет, тому повезло.

В СССР еще до второй мировой войны защитой кораблей от магнитных мин занялся ленинградский Физико-технический институт (ЛФТИ), а в нем - группа сотрудников во главе с А.П.Александровым. Ими фактически с самого начала было выбрано третье направление: вместо решения задачи полной компенсации магнитного поля была поставлена задача существенного уменьшения магнитного поля корабля. До какого уровня?

Среднее значение индукции магнитного поля Земли на всей ее поверхности около $5 \cdot 10^{-5}$ тесла, у магнитных полюсов оно $6,6 \cdot 10^{-5}$ Тл, а на магнитном экваторе $3,4 \cdot 10^{-5}$ Тл. Естественное колебание магнитного поля Земли достигает уровня $(0,1-0,2) \cdot 10^{-5}$ Тл. Чувствительность мины не должна быть выше этой величины, иначе она подорвется безо всяких кораблей. Но это значит, что при компенсации магнитного поля корабля точности размагничивания на уровне $0,1 \cdot 10^{-5}$ Тл вполне достаточно для защиты от магнитных мин.

Решение такой задачи оказалось существенно проще, чем полная компенсация магнитного поля корабля. При этом еще до начала компенсации измерялась карта магнитного поля, создаваемого кораблем.

Были предложены две схемы неполной компенсации: стационарная и нестационарная. По первой схеме (стационарной) на корабле размещалось несколько обмоток, по которым пропускался постоянный ток. При этом магнитное поле от обмоток было приблизительно равно по величине и противоположно по направлению магнитному полю корабля. По второй схеме (нестационарной) происходило динамическое размагничивание корабля. Обмотки, по которым пропускался переменный ток, размещались либо на самом корабле, либо рядом с кораблем (на специальном судне) и после размагничивания убирались. В ходе динамического размагничивания амплитуда магнитного поля постепенно уменьшалась от поля насыщения ферромагнетика до нуля. Такой эффект полного размагничивания был временным, и с течением времени намагничивание снова появлялось. Но при повторении процедуры размагничивания раз в несколько месяцев удавалось поддерживать магнитное поле корабля на низком уровне.

Таким образом можно было уменьшить магнитное поле корабля более чем в десять раз. Это спасло множество кораблей и подводных лодок. Созданная «система ЛФТИ» была внедрена примерно на сотне кораблей и действительно защитила их от немецких магнитных мин.

Интересная особенность данного примера дуэли «вируса» с «маской» касается действующих лиц этого противостояния. Размагничиванием кораблей («маска») в СССР наряду с А.П.Александровым активно занимался И.В.Курчатов. А разработкой и совершенствованием магнитных мин («вирус») в Германии - один из ведущих физиков В. Герлах. Впоследствии Курчатов стал руководителем советской атомной программы, а Герлах возглавил немецкий «Урановый проект». Так что их дуэль продолжилась не только на минном, но и на атомном направлении.

Казалось бы, необходимость в размагничивании кораблей для защиты от магнитных мин - очень давняя, почти забытая 
история. Однако это не так, и в XXI веке на крупных военных кораблях размагничивание остается необходимым, причем используются те же, заложенные давно, принципы размагничивания. Только от медных кабелей обмоток размагничивания, потребляющих много энергии, постепенно переходят к кабелям на основе высокотемпературных сверхпроводников, охлажденных до криогенных температур ( 70 К). Применение высокотемпературных сверхпроводников, одной из современных точек роста передовых технологий, позволяет существенно уменьшить массу обмоток и снизить мощность питания.

\section{Стелс-технологии}

Второй пример касается разработки конструкций самолетов, невидимых для систем обнаружения, что по идее могло бы превратить их в подобие абсолютного оружия (впоследствии эти подходы применялись и в других системах, в частности на подводных лодках). Слово stealth в переводе с английского означает скрытность.

В данном примере стелс-самолет уподобим «маске», гарантирующей неуязвимость со стороны радаров, а сами радары «вирусу», пытающемуся увидеть самолет и «ужалить» (привести в действие системы поражения). Но возможно ли создание абсолютной «маски» большого размера?

В методе обнаружения летящих объектов радарами сигнал от радиолокационной станции уходит в пространство и отражается. На радаре появляется изображение, позволяющее судить об эффективной площади рассеивания. Если обратное отражение радиоволн отсутствует, то объект невидим, эффективная площадь рассеивания равна нулю.

Стелс-технологии самолетов с малой эффективной площадью рассеивания первоначально отталкивалась от двух принципов: нет отражения обратно, есть поглощение в материале корпуса. Более точно, нужно, чтобы радиоволны отражались от объекта так, чтобы обратно не вернуться, и поглощались в корпусе самолета. Это схематично изображено на рисунке 2 . $\mathrm{Pa}$ -

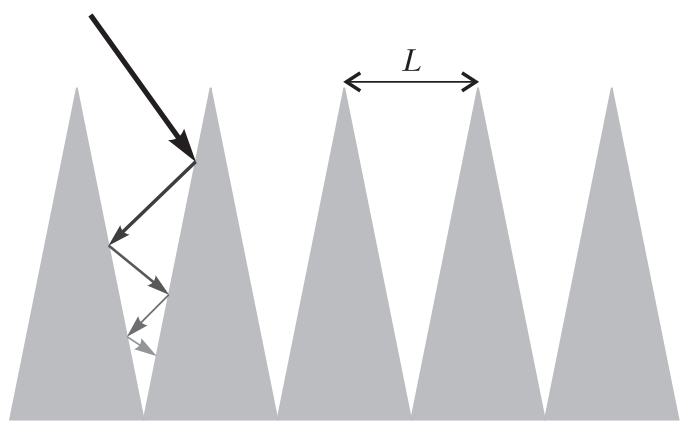

Рис. 2. Схема, поясняющая идею стелс-технологий

диосигнал (стрелка сверху) при распространении внутрь корпуса самолета отражается от элементов конструкции и поглощается в его материале. Обратный возврат сигнала отсутствует.

Казалось бы, измените конструкцию корпуса самолета, перейдя от гладкой, округлой формы к угловатой (опять что-то похожее на шипы коронавируса), и используйте поглощающие покрытия - проблема будет решена. Однако, реализация этих принципов в реальных конструкциях самолетов-«невидимок» послужила лишь толчком к быстрому развитию как систем обнаружения, так и стелс-технологий. При этом стоимость создания систем обнаружения оказалась во много раз меньше стоимости дальнейших шагов в сторону невидимости и неуязвимости. В создании систем обнаружения преуспела Россия, в развитии технологий невидимости - США.

На рисунке 2 показано характерное расстояние $L$ между ребрами. Если длина волны радиосигнала $\lambda$ меньше $L$, то изложенный принцип невидимости объекта должен работать. Первые стелс-самолеты в США создавались в расчете на сантиметровые длины волн радиолокационных станций, работающих на частоте $f \sim 10$ ГГц. Поскольку $\lambda=c / f\left(c=3 \cdot 10^{8} \mathrm{~m} / \mathrm{c}-\right.$ ско- $^{-}$ рость света), то при указанной частоте длина волны $\lambda \sim 3$ см. Но если выбрать длину волны $\lambda \gg L$, то сигнал перестает замечать ребра и отражается. И действительно, переход на меньшие частоты и, соответственно, на большие длины волн (дециметровый диапазон) привел к тому, что самолет-«невидимка» стал заметен для 
таких радиолокационных станций. А если двинуться еще дальше и перейти уже к метровому диапазону волн, т.е. длин волн того же масштаба, что и размер элементов самолета, то малозаметность самолета становится в принципе невозможной. То же относится и к поглощению радиоволн. Для радиоволн с разной длиной волны эффективность их поглощения различна.

Что в итоге? Развитие технологий малозаметности привело к тому, что они стали важным элементом для новых поколений самолетов, ракет и подводных лодок, однако не решают проблему абсолютной защиты. Но прогресс в движении к малозаметности огромен. На самолетах нового поколения принимаются меры по снижению заметности как в радиодиапазоне, так и в видимом, инфракрасном и звуковом диапазонах. В результате эффективная площадь рассеивания для большого дозвукового стратегического бомбардировщика (без стелс-технологий) оказывается по-

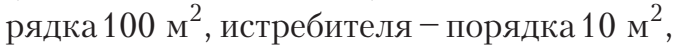
а для современных стелс-самолетов - еще на порядок меньше. Но при этом оказалось, что малозаметные самолеты существенно менее маневренные и менее скоростные. В итоге соперничество между сверхманевренностью и малозаметностью при бурном развитии средств радиолокации продолжается.

Любопытно, что введенное выше понятие эффективной площади рассеивания можно уподобить понятию сечения взаимодействия в физике, по которому судят о параметрах элементарных частиц и характере взаимодействующих полей. При этом сечение одного и того же объекта, скажем протона, в случае взаимодействия с разными частицами может сильно различаться. Пример того, как может выглядеть протон при его взаимодействии с другим протоном, с квантом излучения (фотоном) и с легкой элементарной частицей (нейтрино), приведен на рисунке 3. Как видно из рисунка, в случае рассеяния фотона на протоне могут быть «видны» три кварка, из которых «состоит» протон. Еще четче это видно при рассеянии слабо взаимодействующего нейтрино с протоном. Как и в
Протон с точки зрения

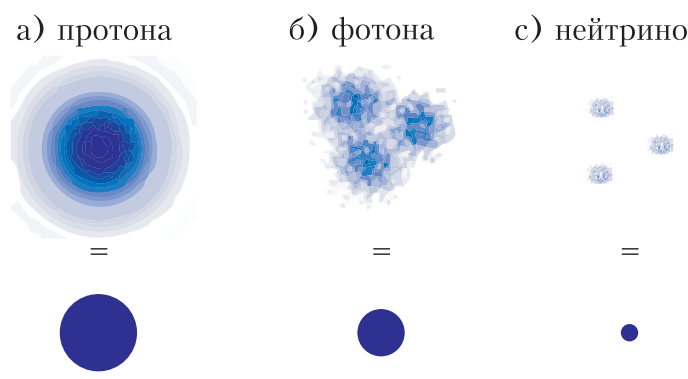

Рис. 3. Эффективное сечение. Мишень во всех трех случаях - протон. Налетающая частица протон; фотон; нейтрино. В нижнем ряду показано отличие в эффективном сечении взаимодействия

случае отражения от самолета радиоволн различного диапазона, сечения взаимодействия могут сильно различаться.

В приведенном сравнении мы чуть коснулись современной модели строения элементарных частиц - так называемой Стандартной модели. ${ }^{2}$ Немного продолжив аналогии, упомянем о современных «элементарных частицах» или «элементах структуры» применительно к проблеме малозаметности в самолетостроении. Это еще одна точка роста в развитии технологий. Речь идет о метаматериалах и особом языке их описания.

В отличие от множества полей взаимодействия элементарных частиц в Стандартной модели - сильное, электромагнитное, слабое и гравитационное - в науке о метаматериалах действует только электромагнитное поле. А вместо набора истинно элементарных частиц Стандартной модели - кварков, лептонов, калибровочных бозонов и бозона Хиггса - используется набор простых электромагнитных резонаторов. Примеры элементарных «кирпичиков», из которых строятся метаматериалы, приведены на рисунке 4 . В результате метаматериал является набором макроскопических элементов из этих «кирпичиков» (и даже более сложных), которые уложены в периодическую структуру, где связу-

2 Подробнее о ней можно прочитать, например, в статье В.Рубакова «К открытию бозона Хиггса» («Квант», 2012, № 5-6). 


\begin{tabular}{|c|c|c|}
\hline \multicolumn{3}{|c|}{ Кусок проволоки } \\
\hline $\begin{array}{c}\text { Разрезанное } \\
\text { кольцо }\end{array}$ & $\begin{array}{c}\text { Нагруженное } \\
\text { кольцо }\end{array}$ & $\begin{array}{c}\text { Двойное } \\
\text { разрезанное } \\
\text { кольцо }\end{array}$ \\
\hline$\Omega$-включение & Спираль & $\begin{array}{c}\text { Бифилярная } \\
\text { спираль }\end{array}$ \\
\hline $\begin{array}{c}\text { Сегнето- } \\
\text { электрический } \\
\text { куб }\end{array}$ & $\begin{array}{c}\text { Сегнето- } \\
\text { электрический } \\
\text { шар }\end{array}$ & $\begin{array}{c}\text { Сегнето- } \\
\text { электрический } \\
\text { рулет }\end{array}$ \\
\hline
\end{tabular}

Рис. 4. Элементы, из которых строятся метаматериалы

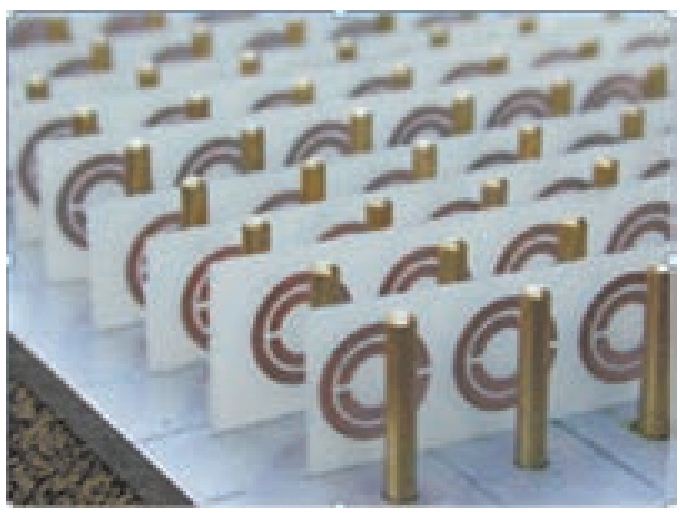

Рис. 5. Структура из метаматериала, включающая комбинации отрезков прямых проволочек и двойных разрезанных колец в диэлектрике

ющим элементом является диэлектрик. Одна из таких структур показана на рисунке 5. Смысл термина «мета» - за пределами - в том, что электромагнитные свойства получающейся структуры радикально отличаются от свойств отдельных элементов.

На рисунке 4 упомянут термин «сегнетоэлектричество». Это явление имеет аналогию с ферромагнетизмом из раздела о размагничивании. При воздействии на железо магнитным полем домены ориентируются вдоль магнитного поля, и мате- риал намагничивается. Аналогично, воздействие электрического поля на сегнетоэлектрик также приводит к ориентации доменов сегнетоэлектрика, которая сохраняется после снятия электрического поля, и материал электризуется.

Использование метаматериалов применительно к проблеме малозаметности самолетов бурно развивается, обещая множество прорывов. В указанных структурах электромагнитные волны распространяются по необычным траекториям, затрудняющим как обнаружение объектов, так и их свойства. Однако на этом пути еще много проблем (невидимость в широком диапазоне частот, сохранение свойств метаматериалов в реальных конструкциях самолетов при большой скорости полета и др.). Кроме того, весь корпус самолета метаматериалами не покрыть. Самолет сложно сделать полностью невидимым, однако можно довольно сильно уменьшить эффективную площадь рассеивания и затруднить его обнаружение радарами.

\section{Коронавирус и защитная маска}

Мы переходим к основному разделу этой статьи. Главный вывод из предыдущих разделов - абсолютной защиты в технике пока не удалось создать, но удается сильно замаскировать объект и затруднить его обнаружение.

В качестве одной из основных и простых мер защиты от нынешней эпидемии коронавируса предлагается повсеместное ношение масок (плюс соблюдение дистанции, плюс более частое мытье рук и т.д.). При этом сразу оговаривается, что маски не гарантируют от заражения. И все же, чуть перефразируя американскую поговорку, отметим, что «доброе слово, подкрепленное цифрой, порой звучит убедительнее, чем просто доброе слово».

Есть два основных пути заражения: воздушно-капельный (при кашле и чихании) и контактный (прикосновения руками к поверхностям, содержащим вирусы). В первом случае вирусы попадают непосредственно на слизистые носа, глаз и рта, во втором возможно их касание грязными «вирусными» руками. Приведем несколь- 
ко цифр, относящихся к вирусам. Они не точные, но могут дать представление о процессах при заражении вирусом. Будем во многом опираться на данные американского иммунолога и популяризатора науки Эрина Бромиджа, но с проверкой этих данных по другим источникам. Заметим, что оценки скорости оседания капель, содержащих вирусы, были приведены в статье А.Стасенко «Не чихать: пандемия!» («Квант», 2020, № 4).

Инфекционная доза, при которой человек заболевает, - около 1000 частиц вируса. Эта цифра очень приблизительна. Она зависит от состояния здоровья человека, его иммунного статуса, возраста и т.д. Но важно отметить, что в случае COVID-19 приводят к заражению не единичные вирусы, а их большое количество, полученное за короткий период времени. С единичными вирусами иммунная система организма чаще всего может справиться.

Кашель сопровождается выбросом нескольких тысяч мелких капель, содержащих вирусы, из которых те, что побольше, падают на землю, а самые мелкие зависают в воздухе. При чихании в воздух выделяется уже десятки тысяч еще более мелких капель. Общее число вирусов, выделяемых (по Бромиджу) при кашле или чихании, оценивается в сотни миллионов. При дыхании, особенно спокойном, через нос выделяется существенно меньшее количество вирусных капель, Бромидж приводит цифру в несколько десятков вирусных частиц в минуту. Если все эти частицы попадают на незараженного человека, то инфекционная доза накапливается в течение примерно часа нахождения вблизи зараженного человека. Разговор больного увеличивает количество выделяемых капель примерно на порядок.

В целом, наиболее опасными для распространения коронавируса являются чихание и кашель. В этом случае использование масок как заболевшими, так и здоровыми, может радикально изменить ситуацию. Некоторую пищу для размышлений о пользе масок дает таблица (рис.6), построенная по опубликованным предварительным результатам работы финских ис-

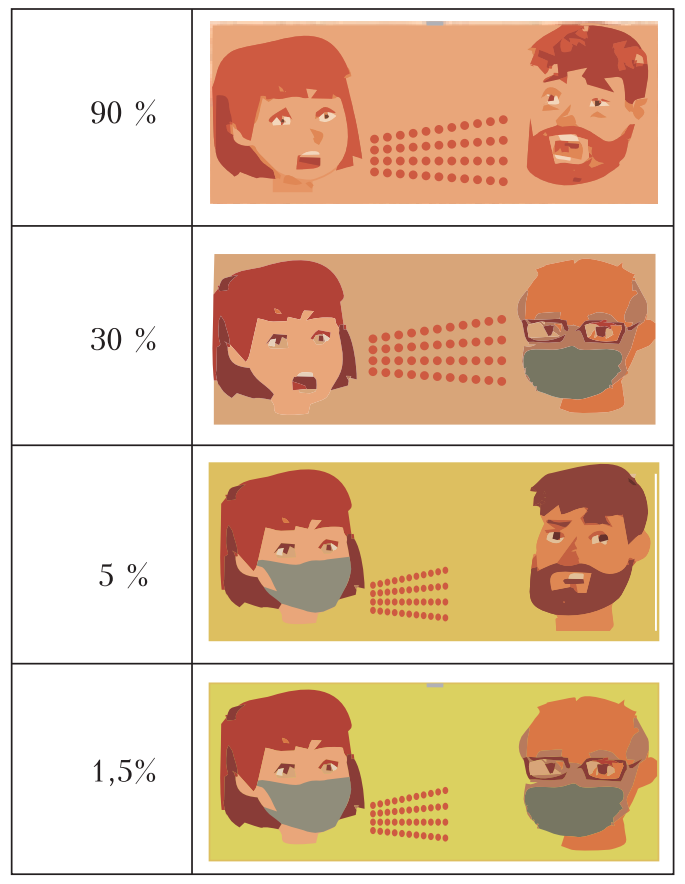

Рис. 6. Риск передачи коронавируса при использовании масок

следователей. Как следует из таблицы, маска задерживает капли, содержащие вирусы, и позволяет существенно снизить опасность заражения. Эффективность использования масок возрастает, если их носят как зараженный, так и здоровый человек. Еще лучше показатели в случае, когда люди в масках находятся на расстоянии друг от друга (риск близок к нулю при расстоянии более 1,5-2 м).

Отметим важную особенность картинок из таблицы: на здоровом человеке кроме маски есть еще и очки. Ведь слизистые глаз являются одним из важных каналов проникновения вируса. Хуже того: вирус, попав в глаза, очень долго сохраняется. Это подтверждается и данными китайских ученых: по их оценкам люди, регулярно носящие очки, в пять раз реже заражаются коронавирусом.

Так что гарантии, как и в предыдущих случаях, нет, но «эффективную площадь заражения» при использовании масок в людных местах все же можно сильно уменьшить. 